\title{
Role of endothelial-microparticles and the tissue factor pathway in ginsenoside Rb1-mediated prevention of umbilical vein endothelial cell injury
}

\author{
MIAOMIAO ZHAO ${ }^{*}$, JUAN XIE $^{2 *}$, HAORUI SHEN $^{1}$, XIAOXIAO WANG $^{1}$, QIULING WU $^{1}$ and LINGHUI XIA ${ }^{1}$ \\ ${ }^{1}$ Institute of Hematology, Union Hospital, Tongji Medical College, \\ Huazhong University of Science and Technology, Wuhan, Hubei 430000; \\ ${ }^{2}$ The First Teaching Hospital of Tianjin University of Traditional Chinese Medicine, Tianjin 300000, P.R. China
}

Received December 12, 2019; Accepted August 20, 2020

DOI: $10.3892 /$ br.2020.1384

\begin{abstract}
Hepatic veno-occlusive disease (VOD) is a life-threatening complication of hematopoietic stem cell transplantation, which urgently requires effective prevention and treatment. Endothelial damage is recognized as the first event in patients with hepatic VOD. However, the mechanism by which endothelial injury induces thrombosis in hepatic VOD is still not clear. In the present study, monocrotaline (MCT) was used to induce endothelial cell injury in EA.hy926 cells to imitate in vitro hepatic VOD. MCT significantly increased apoptosis in EA.hy926 endothelial cells and the secretion of endothelial microparticles (EMPs) which can be used to reflect the level of endothelial injury. Additionally, MCT significantly enhanced the expression of soluble tissue factor (TF) and EMP-bound TF protein, suggesting that EMPs may participate in the development of hepatic VOD by regulating coagulation. Ginsenoside Rb1, a major constituent and effective ingredient of Panax ginseng, was found to significantly decrease MCT-induced endothelial injury and release of EMPs. Moreover, Ginsenoside Rb1 decreased soluble TF released by EA.hy 926 cells and EMP-bound TF protein induced by $\mathrm{MCT}$. These data suggest that ginsenoside Rb1 may serve as a potent prophylactic and/or as a treatment of hepatic VOD by protecting endothelial cells and preventing microthrombosis induced by endothelial injury.
\end{abstract}

Correspondence to: Professor Qiuling Wu or Professor Linghui Xia, Institute of Hematology, Union Hospital, Tongji Medical College, Huazhong University of Science and Technology, 1277 Jiefang Road, Wuhan, Hubei 430000, P.R. China

E-mail: wuqiuling927@hotmail.com

E-mail: linghuixia@hust.edu.cn

*Contributed equally

Key words: endothelial-microparticles, hepatic veno-occlusive disease, hematopoietic stem cell transplantation, ginsenoside, tissue factor, monocrotaline

\section{Introduction}

Hepatic veno-occlusive disease (VOD), also termed sinusoidal obstruction syndrome (SOS), is a potentially life-threatening complication observed following hematopoietic stem cell transplantation (1). Endothelial damage is recognized as the first event of hepatic VOD, which is hypothesized to be caused by glutathione-consuming agents, such as sirolimus, $\mathrm{Bu}, \mathrm{BCNU}$ or TBI, or otherwise previous liver diseases (2-4). Microscopy analysis of hepatic VOD animal models showed that the events following sinusoidal endothelial cell injury included the activation of the coagulation and fibrinolytic pathway (3), which subsequently reduces the flow of sinusoidal blood leading to the formation of microthrombi that obstruct the sinusoidal pores (3). As a result, the development of venule thrombosis and ischemia are observed, ultimately resulting in perivascular hepatocyte necrosis and fibrosis of sinusoids $(4,5)$. However, the mechanism by which endothelial injury induces thrombosis in hepatic VOD is still not clear.

Currently, there are no effective preventative treatment regimens for hepatic VOD $(3,4)$. Defibrotide is the only drug approved for the treatment of VOD in the European Union, but its effect is limited (5). In an international multicenter compassionate-use program performed between December 1998 and March 2016, the estimated overall 100+ day survival in 710 patients with hepatic VOD treated with defibrotide was only 54\%; however, adverse events were reported in $53 \%$ of the patients receiving the drug (6). Recently, a retrospective study evaluated the effect of recombinant human tissue plasminogen activator combined with heparin for the treatment of hepatic VOD, and found that $29 \%$ of patients responded, but the treatment was associated with a significant risk of life-threatening hemorrhage (7). Thus, novel agents with high efficiency and low toxicity are urgently required.

Ginsenoside Rb1 is a major constituent and effective ingredient of Panax ginseng, and is one of the most widely used traditional Chinese herbal medicines, which has been reported to possess several purported effects on the cardiovascular, endocrine, immune and nervous systems, apparently with low side effects $(8,9)$. Ginsenoside Rb1 was also found to effectively prevent vascular endothelial dysfunction 
through the upregulation of ghrelin secretion, nitric oxide production and endothelial nitric oxide synthase protein expression (10-12). It has been shown that ginsenoside Rb1 can effectively block homocysteine-induced endothelial dysfunction in porcine coronary arteries (13). According to these findings, it was hypothesized that ginsenoside Rb1 may help prohibit the development of hepatic VOD with a favorable safety profile by protecting against endothelial injury.

Endothelial microparticles (EMPs), characterized by the surface expression of endothelial antigens such as CD62E (also termed E-selectin), are submicron vesicles released from endothelial cells in response to cell activation, injury or apoptosis and have emerged as new markers of endothelial injury (14-17). It has been reported that under certain pathological conditions such as antiphospholipid syndrome, lupus and several types of cancer, the concentration of EMPs in the blood may increase and contribute to blood coagulation, angiogenesis and inflammation (18-20). In our previous study, an increased presence of EMPs was shown to serve as a marker of endothelial activation in patients with graft vs. host disease (GVHD) following hematopoietic stem cell transplantation (17). Expression of Fas/FasL on EMPs was involved in the development of GVHD, and miRNA155 in EMPs may promote GVHD progression by regulating T cell function (17). Therefore, it was hypothesized that EMPs may participate in GVHD development by regulating coagulation.

Monocrotaline (MCT) is a pyrrolizidine alkaloid phytotoxin that is well established to cause hepatic toxicity in both animals and humans (21-23). Rats treated with MCT have been widely used as an in vivo model of hepatic VOD $(24,25)$. Therefore, in the present study, MCT was used to induce endothelial cell injury in EA.hy926 cells to imitate the endothelial damage caused by hepatic VOD in vitro. Furthermore, the effect of ginsenoside Rb1 on MCT treated EA.hy926 cells and $\mathrm{CD} 2 \mathrm{E}^{+}$-EMPs were assessed, to investigate the molecular mechanisms underlying endothelial protection mediated by ginsenoside Rb1. In addition, the expression of tissue factor (TF) protein on endothelial cells and EMPs was studied, to determine the process by which coagulation abnormalities were induced by endothelial cell injury in hepatic VOD and to determine the value of ginsenoside $\mathrm{Rb} 1$ administration in hepatic VOD/SOS by blocking endothelial injury and thrombosis simultaneously.

\section{Materials and methods}

Cell culture and treatments. The human umbilical vein endothelial cell line EA.hy926 was obtained from The Cell Bank of Type Culture Collection of the Chinese Academy of Sciences. Ginsenoside Rb1 was purchased from The China Food and Drug Administration. Mycoplasma testing was performed on the cells to ensure they were not contaminated. Cells were cultured in DMEM supplemented with $10 \%$ FBS and incubated with $5 \% \mathrm{CO}_{2}$ at $37^{\circ} \mathrm{C}$. Adherent cells were harvested by digestion with trypsin and centrifuged $\left(1,000 \mathrm{x}\right.$ g for $5 \mathrm{~min}$ at $\left.37^{\circ} \mathrm{C}\right)$.

The experiments were divided into the following groups: Control group, ginsenoside Rb1 control group, EA.hy926 cells treated with $160 \mathrm{mg} / \mathrm{l}$ ginsenoside Rb1 alone for $48 \mathrm{~h}$; MCT group, cells treated with $7.5 \mathrm{mM} \mathrm{MCT} \mathrm{for} 48 \mathrm{~h}$; and ginsenoside Rb1+MCT group, treated with 40,80 or $160 \mathrm{mg} / \mathrm{l}$ ginsenoside $\mathrm{Rb} 1$ for $2 \mathrm{~h}$ prior to treatment with $7.5 \mathrm{mM}$ MCT for $48 \mathrm{~h}$. All cell culture results shown are based on at least three individual experiments.

In the preliminary experiments, the protective effect of different concentrations of ginsenoside Rb1 (40, 80, 160 or $200 \mathrm{mg} / \mathrm{l})$ against MCT-induced damage of umbilical vein endothelial cells were assessed, and the results showed that there was no statistically significant difference between 160 and $200 \mathrm{mg} / 1$ ginsenoside Rb1 (data not shown); thus, the maximum effective concentration of ginsenoside Rb1 was deemed to be $160 \mathrm{mg} / \mathrm{l}$. When deciding on the concentration of ginsenoside for the Rb1 control group, the maximum concentration of $160 \mathrm{mg} / \mathrm{l}$ was used in order to exclude the harmful effect of ginsenoside Rb1 on umbilical vein endothelial cells.

Hoechst 33258 staining. In order to visually show that MCT induced cell apoptosis, and that ginsenoside Rb1 protected against MCT-induced apoptosis, Hoechst 33258 staining was used. The cells were cultured in 6-well plates until they were $80 \%$ confluent and then incubated with the aforementioned drugs with $5 \% \mathrm{CO}_{2}$ at $37^{\circ} \mathrm{C}$. The cells were washed with PBS, then fixed with $4 \%$ formaldehyde for $10 \mathrm{~min}$ at room temperature, and subsequently stained with $10 \mu \mathrm{g} / \mathrm{ml}$ Hoechst 33258 at room temperature for $10 \mathrm{~min}$. Finally, after the cells were washed with PBS, morphological changes were observed under a fluorescence microscope.

Flow cytometry analysis of apoptosis. Annexin V-FITC-propidium iodide (PI) double staining assay was used to quantify apoptosis in EA.hy926 cells using FACScan flow cytometer (BD Biosciences). After $48 \mathrm{~h}$ of drug treatment, cells were harvested, washed with ice-cold PBS, resuspended in $250 \mu \mathrm{l}$ binding buffer and incubated with $5 \mu \mathrm{l}$ Annexin V-FITC for $10 \mathrm{~min}$ at room temperature in the dark. Subsequently, samples were washed with binding buffer, resuspended in PBS, counterstained with $5 \mu \mathrm{g} / 1$ PI for $10 \mathrm{~min}$ at room temperature in the dark and analyzed by flow cytometry to identify apoptotic cells. The extent of early apoptosis was determined as the percentage of Annexin $\mathrm{V}^{+} / \mathrm{PI}^{-}$cells.

Collection of EMPs. EMPs were isolated as described previously $(17,26)$. Cell culture supernatants were collected and centrifuged for $10 \mathrm{~min}$ at $3,000 \mathrm{x} \mathrm{g}$ at $4^{\circ} \mathrm{C}$ to remove any detached cells and fragments. The supernatants were then ultracentrifuged at $16,000 \mathrm{x}$ for $1 \mathrm{~h}$ at $4^{\circ} \mathrm{C}$. The EMP-rich pellets were resuspended in PBS and ultracentrifuged again at $16,000 \mathrm{x}$ for $1 \mathrm{~h}$ at $4^{\circ} \mathrm{C}$, and then resuspended in $50 \mu \mathrm{l}$ PBS for use in subsequent experiments.

Detection of EMPs by confocal laser scanning microscopy. First, 50- $\mu$ l aliquots of EMP suspensions were incubated with $20 \mu \mathrm{l}$ phycoerythrin-labeled anti-CD62E (BD Pharmingen; BD Biosciences) at room temperature in the dark for $30 \mathrm{~min}$, and the reaction was stopped with $1.5 \mathrm{ml} \mathrm{PBS}$, then ultracentrifuged at $16,000 \mathrm{x} \mathrm{g}$ for $1 \mathrm{~h}$ at $4^{\circ} \mathrm{C}$. The samples were resuspended in $50 \mu \mathrm{l}$ PBS, mixed with $2 \mu \mathrm{l}$ fluorescent beads (Sigma-Aldrich; Merck KGaA) $1-\mu \mathrm{m}$ in diameter, then added to the microscope slide and immediately analyzed using confocal laser scanning microscopy (magnification, x300; 


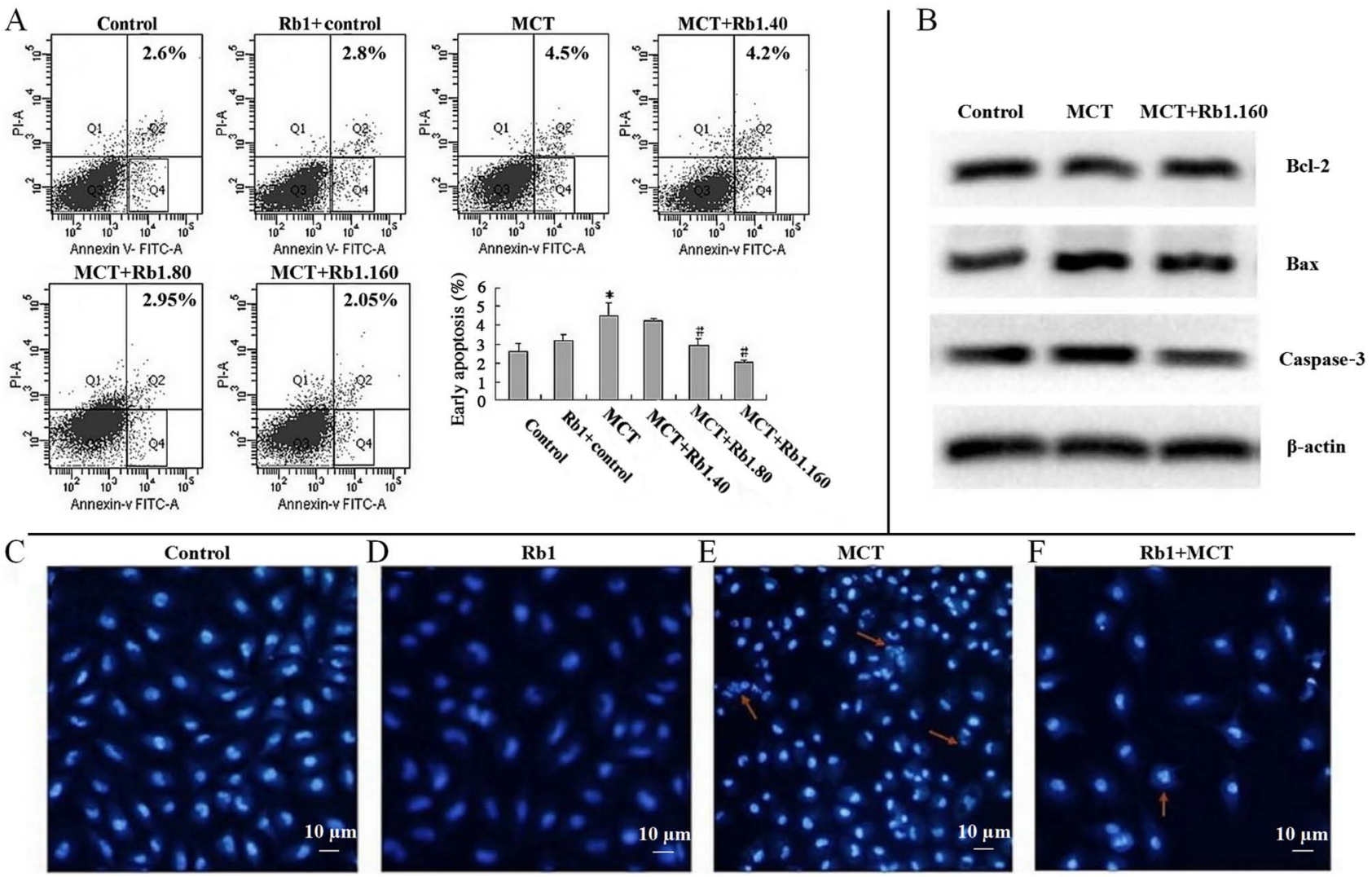

Figure 1. Ginsenoside Rb1 inhibits MCT-induced apoptosis in EA.hy926 cells and inhibits the morphological changes associated with apoptotic cells Annexin $\mathrm{V}^{+} / \mathrm{PI}$-represented the early apoptotic cell group. Scale bar, $10 \mu \mathrm{m}$. (A) Proportion of early apoptotic cells in each group. (B) Expression of apoptosis related proteins. Morphology of cells in the (C) control, (D) Rb1 group, (E) MCT group and (F) MCT+Rb1.160 group. Data are presented as the mean \pm standard deviation of three independent experiments. ${ }^{*} \mathrm{P}<0.05$ vs. control; ${ }^{*} \mathrm{P}<0.05$ vs. MCT group. MCT, monocrotaline; PI, propidium iodide.

Olympus FV500; Olympus Corporation) with excitation and emission wavelengths of 549 and $565 \mathrm{~nm}$, respectively. Differential interference contrast images and fluorescent confocal images were obtained simultaneously.

Flow cytometry analysis for quantification of EMPs. As described above, EMP-rich pellets were suspended in $250 \mu \mathrm{l}$ PBS and analyzed on a FACScan flow cytometer. EMPs were defined as particles $\leq 1.0 \mu \mathrm{m}$ in size positive for the endothelial cell antigen CD62E. Fluorescent beads, $1-\mu \mathrm{m}$ in diameter, were used as the internal standard and for gating the particles.

Western blotting of apoptosis related proteins and TF in cells and EMPs. Detection of apoptosis related proteins was detected in whole-cell lysates. Following the collection of EMPs, the TF bound to EMPs and the soluble TF were separated and preserved in EMP suspensions or the supernatant, respectively. The cells and EMPs were homogenized and lysed separately, in order to further detect the TF proteins bound to each. Subsequently, proteins were loaded on an 8 or $12 \%$ SDS-gel, resolved using SDS-PAGE and transferred to nitrocellulose membranes. The blots were probed with mouse anti-TF (cat. no. 553014; $1: 500$; BD Pharmingen), and anti- $\beta$-actin (cat. no. sc-8432; 1:1,000; Santa Cruz Biotechnology, Inc.) at $4^{\circ} \mathrm{C}$ overnight. Immunoblots were washed and then incubated with horseradish peroxidase-conjugated secondary antibodies (cat. no. 016-030-084; 1:4,000; Pierce; Thermo Fisher Scientific, Inc.) at room temperature for $2 \mathrm{~h}$, and signals were visualized using SuperSignal ${ }^{\mathrm{TM}}$ enhanced chemiluminescence detection (Thermo Fisher Scientific, Inc.) and detected using a chemiluminescence detection system (Bio-Rad Laboratories, Inc.).

ELISA for soluble TF. A commercial ELISA kit (cat. no. RPN1231; Imubind Tissue Factor, American Diagnostica Inc.) was used to detect soluble TF protein in the supernatant medium, according to the manufacturer's protocol. TF protein levels are expressed as $\mathrm{pg} / \mathrm{ml}$ using a reference curve created with TF standards provided with the kit.

Statistical analysis. All data were analyzed using SPSS version 22.0 (IBM Corp.). All results are expressed as the mean \pm standard deviation. A Student's t-test or a one-way ANOVA followed by a Tukey's post-hoc test were used to compare quantitative data populations with normal distributions and equal variances. $\mathrm{P}<0.05$ was considered to indicate a statistically significant difference.

\section{Results}

Ginsenoside Rbl inhibits MCT-induced apoptosis in EA.hy926 cells. As shown in Fig. 1A, after EA.hy926 cells were treated with $7.5 \mathrm{mM}$ MCT for $48 \mathrm{~h}$, the percentage of early apoptotic cells was significantly increased compared with the control group $(4.5 \pm 0.71$ vs. $2.6 \pm 0.42 \%$; $\mathrm{P}<0.05)$. There was no significant difference between the percentage 

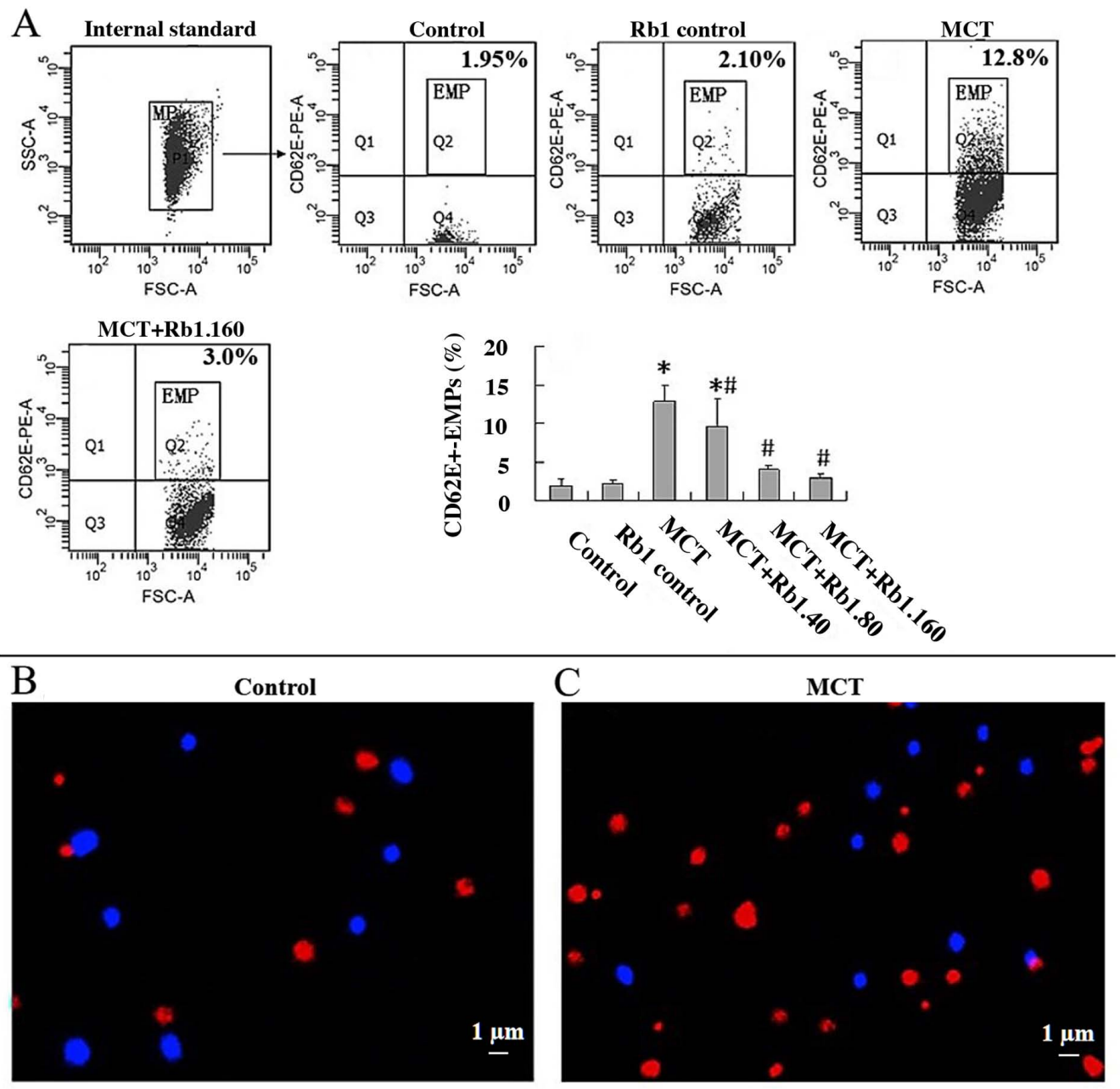

Figure 2. Ginsenoside Rb1 decreases MCT-induced EMP levels in EA.hy926 cells and alters the morphological features of EMPs. Fluorescent beads were used as the internal standard (blue). EMPs appeared as red rounded vesicular structures, with a diameter of $\sim 1 \mu \mathrm{m}$, and were positive for CD62E antibody. Magnification, x400. Scale bar, $1 \mu \mathrm{m}$. (A) Proportion of CD62E ${ }^{+}$-EMPs in the different groups. Confocal microscopy of (B) EMPs in control group and (C) EMPs in the MCT group. Data are presented as the mean \pm standard deviation of three independent experiments. " $\mathrm{P}<0.05$ vs. control; " $\mathrm{P}<0.05$ vs. MCT group. MCT, monocrotaline; EMP, endothelial-microparticles; FSC, forward scatter; SSC, side scatter; PE, phycoerythrin.

of apoptotic cells in the Rb1 control group and the control group, showing the low toxicity of ginsenoside Rbl. However, the percentage of early apoptotic cells was significantly lower in $80(2.95 \pm 0.35 \%)$ or $160 \mathrm{mg} / 1(2.05 \pm 0.07 \%)$ ginsenoside Rb1+MCT groups compared with the MCT group $(4.5 \pm 0.71 \%$; both $\mathrm{P}<0.05$; Fig. 1A).

In addition, similar protective effects of ginsenoside $\mathrm{Rb} 1$ were observed on MCT-induced apoptosis in EA.hy926 cells using fluorescent Hoechst 33358 staining (Fig. 1C-F). Cells treated with $7.5 \mathrm{mM}$ MCT for $48 \mathrm{~h}$ appeared shrunken and dark, and chromatin condensation, marginalization or nuclear beading was observed in the nuclei. Fragmentation of apoptotic nuclei dividing into smaller structures was observed frequently as well (Fig. 1E). However, in the Rb1 control group, only a few typical morphological features of apoptotic nuclei, including pyknotic nuclei and formation of apoptotic bodies, were observed (Fig. 1F).

Ginsenoside Rb1 decreases MCT-induced EMP secretion from EA.hy926 cells. EMPs are cell membrane vesicles derived from endothelial cells. The morphological features of EMPs were confirmed using confocal microscopy. Fluorescent beads $1 \mu \mathrm{m}$ in diameter were used as an internal standard and appeared as blue particles. EMPs appeared as red, rounded vesicular structures with a diameter of $\sim 1 \mu \mathrm{m}$ and were positive for CD62E. The proportion of EMPs in the MCT group was significantly higher compared with control group (Fig. 2B and C).

To further investigate the effect of ginsenoside $\mathrm{Rb} 1$ on MCT-induced EMP secretion, the percentage of CD62 $E^{+}$-EMPs in culture medium in different groups using flow cytometry was determined (Fig. 2A). Cells in the Rb1 control group showed similar levels of $\mathrm{CD}^{2} \mathrm{E}^{+}$-EMPs secretion when compared with the control group $(\mathrm{P}>0.05)$. MCT significantly increased CD62 $\mathrm{E}^{+}$-EMPs production compared with the control group $(12.8 \pm 2.18$ vs. $1.93 \pm 0.86 ; \mathrm{P}<0.05)$. However, exposure of EA.hy 926 cells to 40,80 or $160 \mathrm{mg} / 1$ ginsenoside $\mathrm{Rb} 1$ prior to treating with MCT resulted in a significant decrease in CD62 $\mathrm{E}^{+}$-EMPs production in a dose-dependent manner compared with the MCT group (40 mg/l, 9.67 $\pm 3.57 ; 80 \mathrm{mg} / \mathrm{l}$, $4.08 \pm 0.46 ; 160 \mathrm{mg} / 1,3.00 \pm 0.40$; MCT group, 12.8 \pm 2.18 ; all $\mathrm{P}<0.05$; Fig. 2A).

Ginsenoside Rb1 decreases MCT-induced alterations in TF protein expression levels in EA.hy926 cells. TF is considered an 

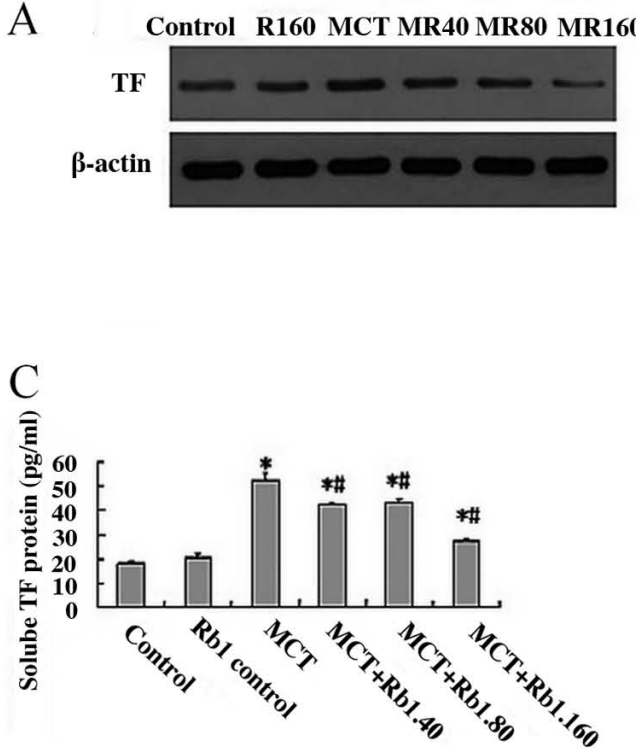

B

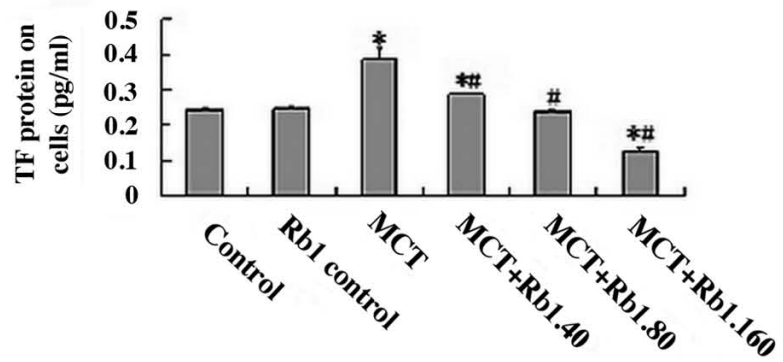

$\mathrm{D}$



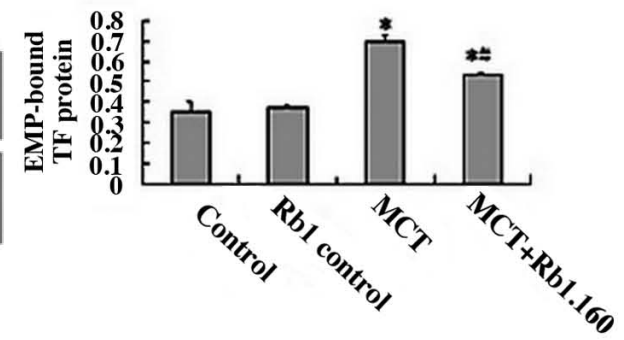

Figure 3. Ginsenoside Rb1 decreases MCT-induced TF protein levels in cells, the secretion of soluble TF proteins in the supernatant medium and EMP-bound TF proteins in EA.hy926 cells. (A and B) TF protein levels in the cells. (C) Soluble TF protein levels in the supernatant medium secreted from the cells in the different groups. (D) Levels of EMP-bound TF proteins in the cells from the different groups. Data are presented as the mean \pm standard deviation of three independent experiments. " $\mathrm{P}<0.05$ vs. control; ${ }^{\#} \mathrm{P}<0.05$ vs. MCT group. MCT, monocrotaline; EMP, endothelial-microparticles; TF, tissue factor.

integral membrane protein expressed at the plasma membrane of endothelial cells that are not exposed to blood. In the present study, the TF protein expression levels on cells were determined by western blotting. The results showed that the levels of TF protein in the MCT group were significantly higher compared with the control group $(0.387 \pm 0.03$ vs. $0.243 \pm 0.09 ; \mathrm{P}<0.05$; Fig. 3A and B). When cells were treated with ginsenoside Rb1 (40, 80 and $160 \mathrm{mg} / \mathrm{l}$ ) and MCT, the protein expression levels of TF protein were significantly decreased in a dose-dependent manner compared with the MCT group (40 mg/l, 0.288 \pm 0.04 ; $80 \mathrm{mg} / 1,0.238 \pm 0.06 ; 160 \mathrm{mg} / 1,0.128 \pm 0.07$; MCT group, $0.387 \pm 0.03$; all $\mathrm{P}<0.05$; Fig. $3 \mathrm{~A}$ and $\mathrm{B}$ ).

Ginsenoside Rbl decreases MCT-induced secretion of soluble (s)TF from EA.hy926 cells. Recently, significantly higher levels of soluble TF proteins were observed in several endothelial related diseases, and these soluble TF proteins possess functions in numerous pathological processes, including hemostasis, thrombosis and inflammation $(27,28)$. In the present study, the supernatant medium of EA.hy926 cells treated with ginsenoside Rb1 and MCT were collected, and the STF levels were detected using ELISA. The results showed that the levels of STF in the MCT group were significantly higher compared with the control groups (52.574 \pm 2.571 vs. $18.121 \pm 0.969 \mathrm{pg} / \mathrm{ml}$, respectively; $\mathrm{P}<0.05$; Fig. 3C). When cells were treated with 40,80 or $160 \mathrm{mg} / \mathrm{l}$ ginsenoside Rb1 combined with MCT, and the levels of sTF were significantly decreased in each group compared with the MCT group (MCT+Rb1.40 group, $42.549 \pm 0.954 \mathrm{pg} / \mathrm{ml}$; MCT+Rb1.80 group, $43.368 \pm 1.712$ pg/ml; MCT+Rb1.160 group $27.538 \pm 1.152 \mathrm{pg} / \mathrm{ml}$; MCT group, $52.574 \pm 2.571 \mathrm{pg} / \mathrm{ml}$; all $\mathrm{P}<0.05$; Fig. 3C).

Ginsenoside Rbl decreases EMP-bound TF protein levels induced by MCT in EA.hy926 cells. To clarify the molecular mechanism underlying the biological effects of EMPs in endothelial damage, the expression of EMP-bound TF proteins were determined by western blotting analysis (Fig. 3D). The results showed that in cells treated with $7.5 \mathrm{mM}$ MCT for $48 \mathrm{~h}$, the expression of EMP-bound TF proteins was significantly increased compared with the control groups (0.704 \pm 0.024 vs. $0.355 \pm 0.0495$; $\mathrm{P}<0.05$; Fig. 3D). However, when cells were treated with $160 \mathrm{mg} / \mathrm{l}$ ginsenoside $\mathrm{Rb} 1$ for $2 \mathrm{~h}$ prior to exposing cells to $7.5 \mathrm{mM} \mathrm{MCT}$ for $48 \mathrm{~h}$, the levels of EMP-bound TF protein were significantly lower compared with the MCT group $(0.536 \pm 0.01$ vs. $0.704 \pm 0.024 ; \mathrm{P}<0.05$; Fig. 3D).

\section{Discussion}

The present study is the first to report that ginsenoside Rb1 prevents endothelial injury through the EMP pathway. Ginsenoside Rb1 significantly decreased MCT-induced EMP levels in EA.hy926 cells and reduced apoptosis. In addition, ginsenoside Rb1 decreased the secretion of soluble TF from EA.hy926 cells and EMP-bound TF protein induced by MCT, and thereby may prevent the development of microthrombosis resulting from endothelial injury.

Ginsenoside Rb1 is an active compound of ginseng, which has been shown to exhibit several pharmacological properties, including anticarcinogenic, immunomodulatory, anti-inflammatory, antiallergic, antiatherosclerotic, antihypertensive and antidiabetic effects, as well as anti-stress activity and effects on the central nervous system (12). Recently, studies have shown that ginsenoside Rbl may prevent hyperhomocysteine-induced endothelial injury and dysfunction and enhance nitric oxide release from endothelial cells (29). The results of the present study showed that ginsenoside Rb1 inhibited MCT-induced apoptosis in EA.hy926 cells in a dose-dependent manner. Additionally, the expression of 
Bax and caspase- 3 proteins, that are promoters of apoptosis, were increased in the MCT group, whereas the expression of Bcl-2 was decreased. However, pretreatment with ginsenoside $\mathrm{Rb} 1$ reversed these alterations; the expression of $\mathrm{Bcl}-2$ was increased, whereas the levels of Bax and caspase-3 were decreased. Bcl-2 is an important apoptosis-inhibiting protein (30). Therefore it was hypothesized that ginsenoside $\mathrm{Rb} 1$ may protect endothelial cells by regulating the expression of apoptosis-related proteins.

In addition, it was also shown that ginsenoside $\mathrm{Rb} 1$ reduced the levels of EMPs which can be used to reflect the level of endothelial injury. A variety of prolonged stimuli are able to induce EMP vesiculation from cultured endothelial cells (16). At low concentrations, EMP generation may serve as an early adaptive response to activated or injured endothelial cells, which protects the endothelium. However, when the number of circulating EMPs exceeds a certain threshold, the EMPs become an important factor exacerbating the pathophysiology of the disease, by directly damaging the endothelium or significantly impairing endothelium-dependent relaxation of macrovessels in vitro (18). The results of the present study showed that ginsenoside Rb1 significantly decreased MCT-induced EMP levels in EA.hy926 cells, suggesting that ginsenoside Rb1 may prevent endothelial injury via an EMP associated pathway.

Compared with the parental cells, cell derived microparticles can exert more potent effects on target organs as they can deliver highly concentrated biological messages including protein, DNA, mRNA and microRNA. In the case of acute injury, endothelial cells may respond by dislodgement-induced EMP generation and EMPs are capable of inducing a procoagulant and thrombotic state (31-33). Coagulant TF has been shown to be an important pathway in these events $(34,35)$. As an essential enzyme activator, TF forms a catalytic complex with FVIIa, and initiates coagulation by activating FIX and FX, ultimately resulting in the formation of thrombin (36). Biologically active TF has been detected in the adventitia of blood vessels, in the circulating blood and in the lipid cores of atherosclerotic plaques (37). Thus, it was hypothesized that EMPs may participate in coagulation via TF. In the present study, TF encapsulation was first detected in EMPs, indicating that TF may circulate in the blood in a stable EMP-bound form, and EMPs may promote inflammation and initiate thrombosis through EMP-bound TF proteins. In addition, it was shown that MCT promoted TF release from endothelial cells, whereas ginsenoside Rb1 significantly decreased the levels of TF and EMP-bound TF protein induced by MCT. These results suggest that ginsenoside Rb1 may prevent endothelial injury by decreasing the expression of TF and therefore reduce microthrombosis and ischemic injury, thus protecting endothelial cells.

The present study has some limitation, including a lack of $3 \mathrm{D}$ reconstruction from the confocal images. Additionally, the mechanisms by which ginsenoside Rb1 exerts its protective effects on endothelial injury require further study.

In conclusion, Ginsenoside Rb1 may serve as a potent agent for the protection of endothelial injury by reducing cell apoptosis and preventing endothelial injury-induced microthrombosis through an EMP-mediated pathway.

\section{Acknowledgements}

Not applicable.

\section{Funding}

This study was supported by the National Natural Sciences Foundation of China (grant no. 30973835).

\section{Availability of data and materials}

The datasets used and/or analyzed during the present study are available from the corresponding author on reasonable request.

\section{Authors' contributions}

QW and LX conceived and designed the study as well as wrote and revised the manuscript. MZ and JX performed experiments, analyzed the data as well as wrote and revised the manuscript. HS and XW assisted in performing experiments. All authors read and approved the final manuscript.

\section{Ethics approval and consent to participate}

Not applicable.

\section{Patient consent for publication}

Not applicable.

\section{Competing interests}

The authors declare that they have no competing interests.

\section{References}

1. Johnson DB and Savani BN: How can we reduce hepatic veno-occlusive disease-related deaths after allogeneic stem cell transplantation? Exp Hematol 40: 513-517, 2012.

2. Roeker LE, Kim HT, Glotzbecker B, Nageshwar P, Nikiforow S, Koreth J, Armand P, Cutler C, Alyea EP, Antin JH, et al: Early clinical predictors of hepatic Veno-occlusive Disease/sinusoidal obstruction syndrome aftermyeloablative stem cell transplantation. Biol Blood Marrow Transplant 25: 137-144, 2019.

3. Dalle JH and Giralt SA: Hepatic Veno-occlusive disease after hematopoietic stem cell transplantation: Risk factors and stratification, prophylaxis, and treatment. Biol Blood Marrow Transplant 22: 400-409, 2016.

4. Corbacioglu S, Jabbour EJ and Mohty M: Risk Factors for development of and progression of hepatic Veno-occlusive Disease/sinusoidal obstruction syndrome. Biol Blood Marrow Transplant 25: 1271-1280, 2019.

5. Dignan FL, Wynn RF, Hadzic N, Karani J, Quaglia A, Pagliuca A Veys P and Potter MN; Haemato-oncology Task Force of British Committee for Standards in Haematology; British Society for Blood and Marrow Transplantation: BCSH/BSBMT guideline: Diagnosis and management of veno-occlusive disease (sinusoidal obstruction syndrome) following haematopoietic stem cell transplantation. Br J Haematol 163: 444-457, 2013.

6. Corbacioglu S, Carreras E, Mohty M, Pagliuca A, Boelens JJ, Damaj G, Iacobelli M, Niederwieser D, Olavarría E, Suarez F, et al: Defibrotide for the treatment of hepatic Veno-occlusive disease: Final results from the international compassionate-use program. Biol Blood Marrow Transplant 22: 1874-1882, 2016.

7. Bagal B, Chandrasekharan A, Chougle A and Khattry N: Low, fixed dose defibrotide in management of hepatic Veno-occlusive disease post stem cell transplantation. Hematol Oncol Stem Cell Ther 11: 47-51, 2018 
8. Cui YC, Pan CS, Yan L, Li L, Hu BH, Chang X, Liu YY, Fan JY, Sun K, Li Q and Han JY: Ginsenoside Rb1 protects against Ischemia/reperfusion-induced myocardial injury via energy metabolism regulation mediated by RhoA signaling pathway. Sci Rep 7: 44579, 2017.

9. Ren S, Leng J, Xu XY, Jiang S, Wang YP, Yan XT, Liu Z, Chen C, Wang Z and Li W: Ginsenoside Rb1, A major saponin from panax ginseng, exerts protective effects against acetaminophen-induced hepatotoxicity in mice. Am J Chin Med 47: 1815-1831, 2019.

10. Wang J, Qiao L, Li Y and Yang G: Ginsenoside Rb1 attenuates intestinal ischemia-reperfusion-induced liver injury by inhibiting NF-kappaB activation. Exp Mol Med 40: 686-698, 2008.

11. Ke L, Guo W, Xu J,Zhang G, Wang W and Huang W: Ginsenoside $\mathrm{Rb} 1$ attenuates activated microglia-induced neuronal damage. Neural Regen Res 9: 252-259, 2014.

12. $\mathrm{Xu} \mathrm{Z,} \mathrm{Lan} \mathrm{T}, \mathrm{Wu} \mathrm{W}$ and $\mathrm{Wu} \mathrm{Y}$ : The effects of ginsenoside $\mathrm{Rb} 1$ on endothelial damage and ghrelin expression induced by hyperhomocysteine. J Vasc Surg 53: 156-164, 2011.

13. Zheng X, Wang S, Zou X, Jing Y, Yang R, Li S and Wang F: Ginsenoside Rb1 improves cardiac function and remodeling in heart failure. Exp Anim 66: 217-228, 2017.

14. Valencia-Nuñez DM, Kreutler W, Moya-Gonzalez J, Alados-Arboledas P, Muñoz-Carvajal I, Carmona A, Ramirez-Chamond R and Carracedo-Añon J: Endothelial vascular markers in coronary surgery. Heart Vessels 32: 1390-1399, 2017.

15. Santilli F, Marchisio M, Lanuti P, Boccatonda A, Miscia S and Davi G: Microparticles as new markers of cardiovascular risk in diabetes and beyond. Thromb Haemost 116: 220-234, 2016.

16. Sierko E, Sokół M and Wojtukiewicz MZ: Endothelial microparticles (EMP) in physiology and pathology. Postepy Hig Med Dosw (Online) 69: 925-932, 2015 (In Polish).

17. Wu Q, Chen H, Fang J, Xie W, Hong M and Xia L: Elevated Fas/FasL system and endothelial cell microparticles are involved in endothelial damage in acute graft-versus-host disease: A clinical analysis. Leuk Res 36: 275-280, 2012.

18. Campello E, Spiezia L, Radu CM, Bulato C, Gavasso S, Tormene D, Woodhams B, Dalla Valle F and Simioni P: Circulating microparticles and the risk of thrombosis in inherited deficiencies of antithrombin, protein $\mathrm{C}$ and protein $\mathrm{S}$. Thromb Haemost 115: 81-88, 2016.

19. Atehortúa L, Rojas M, Vásquez G, Muñoz-Vahos $\mathrm{CH}$, Vanegas-García A, Posada-Duque RA and Castaño D: Endothelial activation and injury by microparticles in patients with systemic lupus erythematosus and rheumatoid arthritis. Arthritis Res Ther 21: 34, 2019.

20. Mobarrez F, Svenungsson E and Pisetsky DS: Microparticles as autoantigens in systemic lupus erythematosus. Eur J Clin Invest 48: e13010, 2018.

21. Xia Q, Zhao Y, Lin G, Beland FA, Cai L and Fu PP: Pyrrolizidine alkaloid-protein adducts: Potential non-invasive biomarkers of pyrrolizidine alkaloid-induced liver toxicity and exposure. Chem Res Toxicol 29: 1282-1292, 2016.

22. Stegelmeier BL, Colegate SM and Brown AW: Dehydropyrrolizidine alkaloid toxicity, cytotoxicity, and carcinogenicity. Toxins (Basel) 8: 356, 2016.

23. Tamariz J, Burgueno-Tapia E, Vázquez MA and Delgado F: Pyrrolizidine Alkaloids. Alkaloids Chem Biol 80: 1-314, 2018.

24. Kleiner DE: The histopathological evaluation of drug-induced liver injury. Histopathology 70: 81-93, 2017.
25. Fang J, Zhang G, Teng X, Zhang Z, Pan J, Shou Q and Chen M: Hematologic toxicity of Gynura segetum and effects on vascular endothelium in a rat model of hepatic veno-occlusive disease. Zhonghua Gan Zang Bing Za Zhi 23: 59-63, 2015 (In Chinese).

26. Wasinee K, Kunwadee P, Kittiphong P, Kovit P, Pornthip C and Saovaros S: Microparticles From $\beta$-thalassaemia/HbE patients induce endothelial cell dysfunction. Sci Rep 8: 13033, 2018.

27. The composition and daily variation of microparticles in whole blood in stable coronary artery disease. J Physiol Pharmacol 69: 6-9, 2018

28. Christersson C, Lindahl B and Siegbahn A: The composition and daily variation of microparticles in whole blood in stable coronary artery disease. Scand J Clin Lab Invest 76: 25-32, 2016.

29. Jia F, Mou L and Ge H: Protective effects of ginsenoside Rb1 on $\mathrm{H}_{2} \mathrm{O}_{2}$-induced oxidative injury in human endothelial cell line (EA. hy926) via miR-210. Int J Immunopathol Pharmacol 33 $1681103269,2019$.

30. Beumer TL, Roepers-Gajadien HL, Gademan IS, Lock TM, Kal HB and De Rooij DG: Apoptosis regulation in the testis: Involvement of Bcl-2 family members. Mol Reprod Dev 56: 353-359, 2000.

31. Sansone R, Baaken M, Horn P, Schuler D, Westenfeld R, Amabile N, Kelm M and Heiss C: Release of endothelial microparticles in patients with arterial hypertension, hypertensive emergencies and catheter-related injury. Atherosclerosis 273 67-74, 2018

32. Jenkins NT, Padilla J, Boyle LJ, Credeur DP, Laughlin MH and Fadel PJ: Disturbed blood flow acutely induces activation and apoptosis of the human vascular endothelium. Hypertension 61: 615-621, 2013.

33. Kou Y, Zou L, Liu R, Zhao X, Wang Y, Zhang C, Dong Z, Kou J, Bi Y, Fu L and Shi J: Intravascular cells and circulating microparticles induce procoagulant activity via phosphatidylserine exposure in heart failure. J Thromb Thrombolysis 48 : 187-194, 2019.

34. Shustova ON, Antonova OA, Golubeva NV, Khaspekova SG, Yakushkin VV, Aksuk SA, Alchinova IB, Karganov MY and Mazurov AV: Differential procoagulant activity of microparticles derived from monocytes, granulocytes, platelets and endothelial cells: Impact of active tissue factor. Blood Coagul Fibrinolysis 28: 373-382, 2017.

35. Geddings JE and Mackman N: Tumor-derived tissue factor-positive microparticles and venous thrombosis in cancer patients. Blood 122: 1873-1880, 2013.

36. Cheng X, Qiu X, Liu Y, Yuan C and Yang X: Trimethylamine $\mathrm{N}$-oxide promotes tissue factor expression and activity in vascular endothelial cells: A new link between trimethylamine N-oxide and atherosclerotic thrombosis. Thromb Res 177: 110-116, 2019.

37. Collier M, Akinmolayan A and Goodall AH: Comparison of tissue factor expression and activity in foetal and adult endothelial cells. Blood Coagul Fibrinolysis 28: 452-459, 2017.

This work is licensed under a Creative Commons Attribution-NonCommercial-NoDerivatives 4.0 International (CC BY-NC-ND 4.0) License. 